\title{
Outcomes in hospital hostels
}

\author{
Geoff Shepherd, Charles King and David Fowler
}

\begin{abstract}
Activity and outcome data for two 'ward-in-a-house' projects for new long-stay in-patients are described. The results confirm that up to a third may be successfully reseltied providing that good qualliy sheltered housing is avallable. However, a simillar proportion appear to find such environments too demanding and may be transferred after an acute exacerbation of symptoms or a violent incident. The remainder need high quality, ongoing care.
\end{abstract}

The existence of a group of patients who are difficult to look after in conventional community accommodation has been recognised for some time. In a classic paper Mann \& Cree (1976) described the characteristics of a national sample of 'new' long-stay (NLS) in-patients defined by a current length of admission of more than one, but less than five, years. They were characterised by severe and intractable symptoms and a variety of additional behavioural and social problems. As mental hospitals have reduced in size, so these individuals have continued to accumulate, often in acute admission wards, exacerbating the shortage of admission beds.

Their overall prevalence varies greatly between different parts of the country (Wykes \& Wing, 1991) and several authors have noted the possible links between incidence rates and indices of social deprivation. Defining criteria have changed over the years, reflecting changing patterns of service provision, and the College Research Unit's recent national audit of NLS used criteria of more than six months continuous admission, but less than three years (Lelliot, 1993, personal communication). The clinical characteristics of the patients may also have changed with increasing pressure on beds - especially in inner cities - and the decreasing availability of alternative placements. There is now an emphasis on so-called "challenging behaviour' problems and an increased recognition of the importance of possible overlap of the NLS with forensic populations (e.g. as in the recent case of Christopher Clunis, Ritchie et al, 1994).

The current placement options for such patients are limited. Again, they vary widely in different parts of the country and, as indicated, many may remain on acute admission wards or in the 'revolving door' of short term admissions and short term tenure in the community. Most are likely to be transferred to traditional hospital wards or 'rehabilitation units' where these exist. Some may end up in prison. Few are likely to be offered care in a specialist, highly supervised, 'haven type' accommodation of the type envisaged in the Ritchie report (para 51.0.6, p 122 op cit). This kind of option has been advocated for some time in the form of 'hospital hostels' or the 'ward-in-a-house' which attempt to combine the best features of high quality hospital care (e.g. high staffing levels, intensive professional input, highly individualised programmes) with a setting which is also homely and domestic in scale and operation (e.g. non-institutional appearance, good access to community facilities, 'normal' expectations of resident involvement in cooking, cleaning, housework). A number of such units have now been established in different parts of the country and their progress has been summarised in Young (1991). The outcome research has also been reviewed in Shepherd (1991) who concluded that although the results were promising, they were clearly not a panacea and some patients did not seem to benefit even from this kind of highly specialised (and quite expensive) care.

It is the purpose of this paper to present outcomes from two hospital hostels established in the Cambridge health district, over a seven and a four year period respectively. We will present some simple descriptive data on patient characteristics, together with information about activities and outcomes. More detailed clinical and social measurements have been taken, but these will be reported separately.

\section{Background}

The Cambridge Health District covers a population of approximately 280,000 people. Since April 1993 mental health services have been provided from within a large general hospital trust (Addenbrookes NHS Trust). The acute psychiatric service is sectorised and the levels of acute bed provision are close to the national norms (24 per 100,000). There is a separate rehabilitation service with long-stay beds in hospital, an active community team, and close links with a variety of non-statutory agencies 
Table 1. Admissions to Number 1 The Drive and Cedars

\begin{tabular}{lll}
\hline & $\begin{array}{c}\text { No. 1 The Ditve } \\
(1986-1993)\end{array}$ & $\begin{array}{l}\text { Cedars } \\
(1989-1993)\end{array}$ \\
\hline n of places & 8 & 12 \\
$n$ of admissions & 21 & 46 \\
Gender & $13(62 \%)$ & $28(61 \%)$ \\
Males & $8(38 \%)$ & $18(39 \%)$ \\
Females & 35.7 & 39.8 \\
Age & 10.2 & 11.7 \\
Mean (years) & $22-55$ & $19-69$ \\
s.d. & $18(86 \%)$ & $38(83 \%)$ \\
range & $2(10 \%)$ & $6(13 \%)$ \\
Diagnosis & $1(4 \%)$ & $2(4 \%)$ \\
Schizophrenia & & \\
Affective psychosis & & $11(24 \%)$ \\
Other & $3(14 \%)$ & $10(22 \%)$ \\
Length of continous in-patient admission prior to entry & $21(46 \%)$ \\
Less than 6 months & $15(71 \%)$ & $4(9 \%)$ \\
6-12 months & $3(14 \%)$ & \\
1-5 years & & \\
More than 5 years & & \\
\hline
\end{tabular}

providing care from a community base. The services have been described in detail in Shepherd et al, (1993) and the range of community provisions was recently used as a 'model' for comprehensive services (Wing, 1992). Levels of social deprivation are relatively low and Cambridge is in the top third of districts according to its 'Jarman' rating. Prevalence rates for new longstay in-patients, defined according to the new College criteria, are close to the national average (around 6/100,000) and the majority are accommodated in the two specialist units described below.

\section{The houses}

Number 1 The Drive was established in 1986 and is located in converted staff accommodation just on the edge of the hospital site. It has eight places and was set up to provide high quality residential rehabilitation for NLS in-patients with no upper time limit on length of stay. Cedars was established in 1989, also in what was originally staff accommodation. It has 12 places and was intended to target those patients who had the best chance of resettlement within two to three years. Both units are well staffed with a total nursing complement of 12 WTE for No. 1 and 13 WTE for Cedars (in both cases this includes $n=4$ WTE night staff). This should give a minimum of two staff on duty at any one time, including at night. The units share a full-time occupational therapist and each receives sessional inputs from psychiatrists (approximately two sessions per week), two psychologists (approximately two sessions each) and a social worker.

In both houses the residents receive highly individualised programmes of care which attempt to involve them in the routines of daily living as much as possible. Progress is carefully recorded in the care plans and fed back to the patients at regular intervals (sometimes daily). Residents and staff are jointly responsible for all the domestic activities in the houses (shopping, cooking, cleaning, etc.) and most are also engaged in day programmes, either on the hospital site or in the community. Every attempt is made to involve residents in decisions regarding their clinical care (e.g. self-care routines, allocation of house chores, choice of daytime activities, etc.). Staff receive continual training and support, particularly from the two psychologists involved, and there is an emphasis on the importance of high quality, 'low EE' interactions. There is also ongoing contact with residents' families wherever possible.

\section{Activity and outcomes}

Table 1 shows the demographic characteristics of admissions to the two units from their establishment until 31 March 1993. It can be seen that both units catered for mainly males, with an average age between 35 and 40, and a predominant diagnosis of schizophrenia or other psychosis. The majority of admissions had spent at least six months continuously as in-patients prior to transfer, although in the 'Cedars' unit just under 
Table 2. Outcomes and lengths of stay

\begin{tabular}{|c|c|c|}
\hline & $\begin{array}{l}\text { No. I The Dive } \\
\text { (1986-1993) }\end{array}$ & $\begin{array}{l}\text { Codars } \\
\text { (1989-1993) }\end{array}$ \\
\hline $\begin{array}{l}\text { Discharged to community } \\
\text { Lengths of stay }\end{array}$ & $8(38 \%)$ & $19(41 \%)$ \\
\hline Mean (months) & 22.9 & 10.9 \\
\hline Median & 13.5 & 10.0 \\
\hline Range & $9-55$ & $3-22$ \\
\hline Transfers & 5 (24\%) & $16(33 \%)$ \\
\hline $\begin{array}{l}\text { to acute ward } \\
\text { to "traditional" }\end{array}$ & 2 & 3 \\
\hline long-stay ward & 3 & 6 \\
\hline to hospltal hostel & - & 6 \\
\hline to other hospltal & - & 1 \\
\hline \multicolumn{3}{|l|}{ Lengths of stay } \\
\hline Mean (month) & 25.6 & 11.1 \\
\hline Median & 30.0 & 8.5 \\
\hline Range & $7-44$ & $1-41$ \\
\hline Ongoing & $8(38 \%)$ & 11 (24\%) \\
\hline \multicolumn{3}{|l|}{ Lengths of stay } \\
\hline Mean (months) & 25.9 & 9.8 \\
\hline Median & 13.0 & 9.0 \\
\hline Range & $3-89$ & $2-21$ \\
\hline
\end{tabular}

a quarter had been in hospital for less. Both units accepted a few patients with current lengths of continuous admission greater than five years. Data regarding their clinical and social functioning (not reported here) confirm that they are a highly disabled group, with severe residual positive and negative symptoms and a range of other behavioural problems.

The outcomes for these admissions, together with their lengths of stay are shown in Table 2. These data show that in both houses approxmately $40 \%$ of admissions were discharged into the community after an average length of stay of around one year. In all cases they were resettled into hostels run by local housing associations or other voluntary agencies with high levels of support (24 hour supervision) but 'sleeping, as opposed to waking, night cover. Cedars seems to be meeting its target of resettling people within two years, although there was a considerable range of lengths of stay in both houses, with one resident in No. 1 being discharged after more than four and a half years. In both units a significant minority of the admissions (24-33\%) were transferred to some other facility, usually ending up in a traditional long-stay ward. This was often as a result of some kind of violent incident, or a sudden increase in the severity of their symptoms. It was sometimes preceded by a short admission to an acute ward. Cedars also transferred six individuals to No. 1 The Drtue when staff decided that it was unlikely that they would be resettled within two or three years. Lengths of stay among the transferred group showed considerable variability, Cedars generally transferring people within 12 months, whereas No. 1 often persisted for more than two years. In both cases, there were individuals who remained in the unit for well over three years before the decision to transfer was taken. Between a quarter and two-fifths of the admissions were ongoing, with average lengths of stay of one to two years. As might be expected, current length of stays were shorter in the Cedars unit. Only one resident had actually been in No. 1 since it first opened (89 months) and since these figures were compiled she has also been successfully resettled in the community.

\section{Comment}

Given that these patients represent the most difficult individuals in terms of the severity and duration of their problems currently presenting to the mental health services in the district, these outcomes are encouraging. More than $80 \%$ of the referrals had spent at least six months continuously in hospital prior to admission and yet almost a third were resettled successfully into the community with an average length of stay of less than 18 months. This reflects the good quality of care provided in the units and the good range of community accommodation avallable in the district. It is also consistent with the results obtained in similar projects elsewhere (Young, 1991; Shepherd, 1991). Our experience supports the suggestion that within this group most 


\section{ORIGINAL PAPERS}

change is likely to occur in the first two to three years; however there are also examples of individuals being successfully resettled after much longer periods. It is also clear that the units were not successful in resettling all potential referrals. Some required this intensive level of input just to maintain their functioning, while others were transferred, often in the context of a violent incident or a marked increase in the severity of their symptoms. However, it is noteworthy that this did not always happen quickly and in most cases people would stay for at least six months before a decision to transfer was taken.

These data are, of course, of only limited value. Nevertheless, they highlight some of the potential and some of the possible limitations of such facilities. They suggest that they may be suitable for the majority of these very difficult 'new' longstay in-patients. However, their effectiveness will be determined not only by the quality of care provided in the houses themselves, but also by the adequacy of the supported housing available locally. There are also some individuals who clearly do not do well and seem to find the settings too difficult and demanding. The proportion falling into this category (a quarter to a third in our sample) may well vary depending on the characteristics of the local catchment area. We are currently examining the detailed data regarding the social and clinical functioning of all the residents and their progress over time in an attempt to identify predictors for these different outcome groups.

\section{Acknowledgements}

The authors would like to acknowledge the contribution of all the staff who helped in the collection of these data, particularly the nursing staff Judy Dean, Willy Harper, Niel Harmer and Tina Thomas.

\section{References}

MANN, S. \& CREE, W. (1976) 'New' long stay psychiatric patients: a national sample survey of fifteen mental hospitals in England and Wales 1972/73. Psychological Medicine 6, 603-616.

RitchIE, J.H., Dick, D. \& LINGHAM, R. (1994) The Report of the Inquiry into the Care and Treatment of Chrtstopher Clunis. HMSO: London.

SHEPHERD, G. (1991) Psychiatric rehabilitation for the 1990s. In Theory and Practice of Psychiatric Rehabllitation (eds. F.N. Watts and D.H. Bennett). Chichester: John Wiley.

-. Singh, K. \& MuLs, N. (1993) Community services for the long-term mentally ill: a case example - the Cambridge Health District. In Dimensions of Communty Care (eds. M. Weller and M. Muijen). London: Saunders:

WING, J.K. (1992) Epidemiologically-Based Mental Health Needs Assessments. London: Royal College of Psychiatrists.

WYKES, T. \& WING, J.K. (1991) 'New' long-stay patients: the nature and size of the problem. In Residential Needs of Severely Disabled Psychiatric Patients - The Case for Hospital Hostels. (ed. R. Young). London: HMSO.

YouNG, R. (1991) Residential Needs of Severely Disabled Psychiatric Patients-The Case for Hospital Hostels. London: HMSO.

*Geoff Shepherd, Head Of Research, Sainsbury Centre for Mental Health, 134-138 Borough High Street, London SE1 ILB; Charles King and David Fowler, Department of Psychology, Fulbourn Hospital, Cambridge CB1 5EF

*Correspondence 